\title{
SARS-COV-2 (COVID-19) has neurotropic and neuroinvasive
}

\section{properties}

\author{
Gonzalo Flores ${ }^{1}$ \\ ${ }^{1}$ Benemerita Universidad Autonoma de Puebla
}

July 1, 2020

Now, we know that the first report of Severe Acute Respiratory Syndrome Coronavirus-2 (SARS-CoV-2) was in December 2019 in Wuhan, China. In January, the existence of a disease caused by a virus with respiratory tropism for humans was announced, and in February it was already named SARS-Cov-2. The World Health Organization (WHO) ${ }^{1}$ gave it the name of COVID-19, on February 11. One month later, WHO declared that the disease caused by this virus was already a pandemic (WHO, 2020) ${ }^{1}$. The virus started in China, then affected other Asian countries such as Japan, South Korea, etc., and later spread to Europe, then America.

As this pandemic progresses, the reports of this six-month period show that this SARS-CoV-2 coronavirus not only targets the respiratory system, its effect on the cardiovascular, digestive, and renal apparatus has also been described. In addition, recent reports have described a set of neurological symptoms ${ }^{2-4}$. Furthermore, the presence of this virus in the neurons and the capillary endothelium of the frontal cortex was seen in a patient who died of SARS-CoV-2 $2^{4}$. Moreover, other reports have shown its presence in the brainstem and in the cerebrospinal fluid (CSF) of other patients with SARS-CoV-2 ${ }^{5-6}$. Recent reports suggested that the cells with the expression of the angiotensin-converting enzyme 2 (ACE-2) may be a target for this coronavirus, since ACE 2 is a suggested cellular receptor for this coronavirus ${ }^{4,7-8}$. Interestingly, various reports have demonstrated the presence of ACE-2, in both neurons and glial cells ${ }^{7,9-11}$. Consequently, the evidence suggests that central nervous system (CNS) may be a target organ for this virus. It is known that the presence of this virus is responsible for the inflammatory process, which causes damage not only at the pulmonary level, but also at the cardiovascular, renal, and digestive system levels. All of these structures have a great regenerative capacity and thus reduce the damage in the long term. However, an inflammatory process at the CNS level could leave sequelae that, with age, could favor the early appearance of neurodegenerative processes, such as Alzheimer's disease, Parkinson's disease, vascular type dementia, multiple sclerosis etc., ${ }^{12-13}$. Consequently, preventive measures should be taken to avoid the CNS from suffering future damage.

Autopsy of patients with COVID-19 has shown that the brain tissue is hyperemic, edematous, and has degenerated neurons ${ }^{2,7}$. However, it is necessary to know the percentage of cases in which there were changes in the nervous tissue caused by SARS-CoV-2, the types of modifications and the CNS regions most affected by COVID $\backslash$ sout-19. Data can help us know the impact on the brain tissue of this viral infection. In addition to supporting the neuroinvasive effect on the CNS and peripheral nervous system (PNS) of this coronavirus, there are the reported cases of meningitis, encephalitis, and Guillain-Barré syndrome associated with SARS-CoV-2 ${ }^{7,14-17}$.

The clinical picture of SARS-CoV-2 is very wide, with symptoms and signs that involve the respiratory, cardiovascular, renal, digestive, and hepatic systems. However, there are also symptoms in which the CNS and PNS could be involved ${ }^{2,3}$. Neurological manifestations have been classified as non-specific and specific by various authors ${ }^{2,15,18-20}$. Among the non-specific ones are headache, fatigue, dyspnea, etc. While the 
specific ones imply clear CNS or PNS affection data, such as loss of smell and reduction of taste and vision, neural pain, epileptic seizures, acute cerebrovascular disease, and deterioration of the state of consciousness have also been reported ${ }^{3,14,15,17,19,20}$.

The way in which the SARS-CoV-2 can reach neurons and glial cells is through the blood crossing the bloodbrain barrier or by retrograde transport through peripheral nerves. There is evidence for both hypotheses. At the beginning of the disease, patients with COVID-19 may have alterations or loss of smell and taste, probably because the virus may damage this pathway, which has been reported to recover, in some cases at the end of the disease and in others up to several weeks after the patient recovered ${ }^{20}$. The virus can pass through the olfactory pathway, which enters the brain through the cribiform plate (transcribial route) $5,7,21$. This route has been reported for other viruses, including SARS-CoV ${ }^{7,18,22}$. In addition, various reports have detected various viruses with respiratory tropism, including some coronaviruses, can reach the brain by retrograde transport, due to their neurotropic properties $5,7,21,22$.

Moreover, there is a percentage of patients who enter the ICU and require ventilatory assistance, since they do not breathe spontaneously ${ }^{7,21,23}$. Consequently, it is necessary to study whether this effect of COVID-19 is due to direct action on lung tissue or due to its neurotoxicity at the level of the brainstem, by affecting the respiratory center, which responds to changes in blood $\mathrm{pH}$ and $\mathrm{CO}_{2}$ levels ${ }^{24}$.

In summary, more studies are required to obtain additional information on the neurotoxic effects of COVID19. However, with the aforementioned data, we can suggest that this coronavirus has neurotropic properties with neuroinvasive activity, which should be investigated, looking for therapeutic tools to reduce the damage that could be left at the nervous tissue level.

\section{References}

1. World Health Organization, Novel Coronavirus (2019-nCoV) Situation Report - 22, 2020

2. Mao L, Jin H, Wang M, Hu Y, Chen S, He Q, Chang J, et al., Neurologic manifestations of hospitalized patients with coronavirus disease 2019 in Wuhan, China. JAMA Neurol . 2020;77;1-9.

3. Helms J, Kremer S, Merdji H, Clere-Jehl R, Schenck M, Kummerlen C, Collange O, et al., Neurologic Features in Severe SARS-CoV-2 Infection. N Engl J Med . 2020;382;2268-2270.

4. Paniz-Mondolfi A, Bryce C, Grimes Z, Gordon RE, Reidy J, Lednicky J, Sordillo EM, Fowkes M. Central nervous system involvement by severe acute respiratory syndrome coronavirus-2 (SARS-CoV2). J Med Virol . 2020;92;699-702.

5. Bulfamante G, Chiumello D, Canevini MP, Priori A, Mazzanti M, Centanni S, Felisati G. First ultrastructural autoptic findings of SARS-Cov-2 in olfactory pathways and brainstem. Minerva Anestesiol . 2020 .

6. Moriguchi T, Harii N, Goto J, Harada D, Sugawara H, Takamino J, Ueno M, et al., A first case of meningitis/encephalitis associated with SARS-Coronavirus-2. Int J Infect Dis . 2020;94;55-58.

7. Baig AM, Khaleeq A, Ali U, Syeda H. Evidence of the COVID-19 Virus Targeting the CNS: Tissue Distribution, Host-Virus Interaction, and Proposed Neurotropic Mechanisms. ACS Chem Neurosci . 2020;11;995-998.

8. Yan R, Zhang Y, Li Y, Xia L, Guo Y, Zhou Q. Structural basis for the recognition of SARS-CoV-2 by full-length human ACE2. Science . 2020;367;1444-1448.

9. Yamagata R, Nemoto W, Nakagawasai O, Takahashi K, Tan-No K. Downregulation of spinal angiotensin converting enzyme 2 is involved in neuropathic pain associated with type 2 diabetes mellitus in mice. Biochem Pharmacol . 2020;174;113825.

10. Mukerjee S, Gao H, Xu J, Sato R, Zsombok A, Lazartigues E. ACE2 and ADAM17 Interaction Regulates the Activity of Presympathetic Neurons.Hypertension. 2020;74;1181-1191.

11. Kehoe PG, Al Mulhim N, Zetterberg H, Blennow K, Miners JS. Cerebrospinal Fluid Changes in the Renin-Angiotensin System in Alzheimer's Disease. J Alzheimers Dis. 2019;72(2):525-535.

12. Cairns DM, Rouleau N, Parker RN, Walsh KG, Gehrke L, Kaplan DL. A 3D human brain-like tissue model of herpes-induced Alzheimer's disease.Sci Adv. 2020;6; eaay8828. 
13. . Flores G, Flores-Gómez GD, Gomez-Villalobos MJ. Neuronal changes after chronic high blood pressure in animal models and its implication for vascular dementia. Synapse. 2016;70;198-205.

14. Dalakas MC. Guillain-Barré syndrome: The first documented COVID-19-triggered autoimmune neurologic disease: More to come with myositis in the offing. Neurol Neuroimmunol Neuroinflamm . 2020;7; e781.

15. Faucher A, Rey PA, Aguadisch E, Degos B.Isolated post SARS-CoV-2 diplopia. J Neurol. 2020;1-2.

16. Joob B, Wiwanitkit V. COVID-19 and Guillain-Barré syndrome. Rev Neurol (Paris), 2020.

17. Wang L, Shen Y, Li M, Chuang H, Ye Y, Zhao H, Wang H. Clinical manifestations and evidence of neurological involvement in 2019 novel coronavirus SARS-CoV-2: a systematic review and metaanalysis. J Neurol . 2020;1-13.

18. Asadi-Pooya AA, Simani L Central nervous system manifestations of COVID-19: A systematic review. J Neurol Sci . 413,116832..

19. Kanwar D, Baig AM, Wasay M. Neurological manifestations of COVID-19. J Pak Med Assoc. 2020;70(Suppl 3), S101-S103.

20. Kosugi EM, Lavinsky J, Romano FR, Fornazieri MA, Luz-Matsumoto GR, Lessa MM, Piltcher O, Sant'Anna GD. Incomplete and late recovery of sudden olfactory dysfunction in COVID-19. Braz J Otorhinolaryngol , 2020;S1808-8694, 30059-30068.

21. Baig, A.M. Neurological manifestations in COVID-19 caused by SARS-CoV-2. CNS Neurosci Ther . 2020;26;499-501.

22. Bohmwald K, Gálvez NMS, Ríos M, Kalergis AM. Neurologic Alterations Due to Respiratory Virus Infections. Front Cell Neurosci . 2018;12;386.

23. Li YC, Bai WZ, Hashikawa T. The neuroinvasive potential of SARS-CoV2 may play a role in the respiratory failure of COVID-19 patients.J Med Virol . 2020;92;552-555.

24. Guyenet PG, Bayliss DA. Neural Control of Breathing and CO2 Homeostasis. Neuron. 2015;87;946-961. 